\title{
Foreign Language Competence in Content and Language Integrated Courses
}

\author{
David Lasagabaster*
}

University of the Basque Country, Facultad de Letras, Paseo de la Universidad 5, 01006 Vitoria- Gasteiz, Spain

\begin{abstract}
European educational systems are making great efforts to improve students' command of foreign languages, as there are many students who leave compulsory education with only the most limited ability to communicate in a foreign language. In this context the implementation of CLIL (Content and Language Integrated Learning) courses is becoming commonplace throughout Europe, because this approach is believed to significantly improve overall language competence in the target language. This paper examines the implementation of CLIL in the Basque Country (Spain), a bilingual community in which both Basque and Spanish are official languages and where English represents the third language included in the curriculum. The results show that the CLIL approach is successful and helps to improve students' foreign language competence even in bilingual contexts where English has little social presence.
\end{abstract}

Keywords: Content and Language Integrated Learning (CLIL), bilingualism, language competence, gender, sociocultural status.

\section{INTRODUCTION: LANGUAGE PROFICIENCY IN EUROPE TODAY}

All European educational systems are attaching increasing importance to the learning of foreign languages, since there is a dire need to educate multilingual and multicultural citizens in a context where the linguistic consequences of globalization are more and more evident. The European Commission [1] authorized a Special Eurobarometer on Europeans and their languages, one of the objectives of which was to gather information regarding the foreign language ability of Europeans. Fieldwork was completed between November and December 2005 and the results were published in 2006. This macro-survey involved no fewer than 28,694 interviews.

The results showed that, while $56 \%$ of European citizens could hold a conversation in a language other than their L1 and $28 \%$ had mastered two other languages, for a remarkable $44 \%$ communication in a language other than their mother tongue was highly implausible. There were remarkable differences between countries. 92\% of citizens in Luxembourg could speak two languages apart from their L1, but almost every single Luxembourger (99\%) could hold a conversation in at least one language apart from the L1. Luxembourg, Malta, Slovakia, Latvia, Lithuania, the Netherlands, Slovenia and Sweden make up the top 8 of countries where nine out of ten inhabitants can speak at least two languages.

Spain and Italy represent the other side of the coin, as $56 \%$ and 59\% of their citizens admit to being monolingual. Similarly, the percentage of Spanish (17\%) and Italians $(16 \%)$ who can hold a conversation in two other languages is among the lowest among the European member states. Curi

*Address correspondence to this author at the University of the Basque Country, Facultad de Letras, Paseo de la Universidad 5, 01006 VitoriaGasteiz, Spain; E-mail: david.lasagabaster@ehu.es ously enough (or just a sign of the times), the only two countries whose percentages are lower turn out to be English speaking countries, that is to say, the United Kingdom and Ireland.

From the macro-survey of 2006, it is clear that language skills are slightly better in relatively small EU member states such as Luxembourg, Malta, the Netherlands and Slovenia, and that citizens of southern European (Italy and Spain among them) and the two English speaking countries (the United Kingdom and Ireland) are less well skilled in second and third languages. However, all education authorities are well aware of the need to boost the learning of foreign languages and to cater for this social demand.

The aforementioned globalizing process is forcing European education systems to pay more and more attention to the learning of foreign languages. Consequently, European schools and universities are offering courses taught in foreign languages, exposing students to teaching through the medium of a foreign language [2]. As a result of this desire to improve foreign language skills, the implementation of CLIL (Content and Language Integrated Learning) programmes is becoming commonplace throughout the continent [3], in the belief that this kind of approach is the best way to improve students' command of foreign languages without devoting too much time to their teaching. This is especially so in bilingual communities such as the Basque Country in Spain, where the two official languages (Basque and Spanish) are also present in the curriculum. This means that students have to deal with three languages and therefore the time allotted to each of them becomes a key (and more often than not, controversial) issue in language planning.

With this context in mind, this study addresses the analysis of the purported benefits of CLIL programmes on language proficiency by focusing on a bilingual context where the foreign language (English) has very little presence outside the school setting. The influence of students' gender and 
sociocultural status will also be examined, as little attention has been paid to these two variables in the CLIL literature.

\section{CONTENT AND LANGUAGE INTEGRATED LEARN- ING (CLIL)}

The label CLIL coexists with others used to include language and content, such as content-based language instruction, content-enhanced teaching, integration of content and language, theme-based language teaching, content infused language teaching, foreign language medium instruction, bilingual integration of language and disciplines, learning through an additional language, foreign languages across the curriculum, or learning with languages, to name but a few. The 2006 Eurydice Survey analyzes CLIL programmes in 30 European countries and comes to the conclusion that different labels are used in different contexts, which is why the reader can come across manifold labels for CLIL in literature on the subject. Coyle [4] points out that "whilst CLIL shares some elements with many of these approaches, in essence its distinctiveness lies in an integrated approach, where both language and content are conceptualised on a continuum without an implied preference for either". It seems the cornerstones of CLIL are on the one hand the above mentioned integrated approach, and on the other hand, the European framework, in the sense that CLIL programmes are rooted in very diverse European contexts due to their own sociolinguistic and political features [5]. Nowadays, the acronym CLIL has become pre-eminent for this kind of provision in the world of research [6].

One of the most topical issues in many European education systems is whether it is better to start foreign language teaching at an early age, or whether it is better to include CLIL courses at a later stage -without establishing an early first contact with the foreign language. Although research undertaken in naturalistic settings confirms that young starters ultimately achieve higher competence in the L2, studies carried out in school settings are not so definitive and, in fact, they usually conclude that older starters show a faster rate of acquisition [7]. In the same vein, studies completed in the Canadian context demonstrate that late immersion students perform as well as early immersion students in some language assessments, despite the latter having accumulated two to three times more instruction learning the L2 [8]. Studies completed in formal learning contexts have thus recurrently shown that older learners are faster and better learners than younger ones in most aspects of acquisition, even in the case of pronunciation, the skill that -at least from a theoretical point of view- may benefit most from this early start [9, 10].

However, folk beliefs are playing a paramount role in this respect, as it is widely held that the younger, the better in foreign language learning, despite the previously mentioned empirical evidence which demonstrates that this is not always the case in formal language learning contexts such as school. One of the main reasons lies in the idea that children are supposed to be better at acquiring languages implicitly (whereas older students and adults benefit more from explicit teaching), and for this implicit learning to take place, massive amounts of input are needed. As a result of this, it is similarly believed that this implicit learning can only be provided in second language naturalistic contexts or in immer- sion programmes [11]. This belief is shared not only by parents, but also by teachers and language planners, which is why most European governments have decided to lower the starting age of learning a foreign language [12, 13]. Nevertheless, this is an issue which is becoming controversial in some contexts.

In fact, Egiguren [14] observed that the early teaching of English may not be the only course of action. This author compared two groups of students, the first one made up of students who started to learn English at the age of 4, and the second one at 8 , but the latter also had two hours per week of Arts taught in English. In this case no differences were found when the participants' proficiency in English was compared at the age of 10, which leads Egiguren to conclude that the early teaching is not the only possibility when it comes to improving our students' command of English, as in just a year and a half the late starters had already caught up with the early starters thanks to the CLIL approach.

The findings obtained by Egiguren seem to support the implementation of CLIL programmes, since the particular features of formal settings such as school appear to benefit older learners in the short term due to their being at a more developed cognitive stage (which gives them an advantage when it comes to test-taking), whereas young learners cannot take advantage of the necessary exposure and contact with the L2 [15]. Similarly, the implementation of a CLIL approach augments the presence of the foreign language in the curriculum without increasing students' time commitment. This creates a context in which the foreign language is used to transmit information in real communicative situations and therefore language learning takes place in a more meaningful and efficient way.

\section{THE PURPORTED BENEFITS OF CLIL}

The CLIL approach has been praised on many different grounds $[16,17]$. It is believed to help prepare students for internationalization, a key word for all education systems due to the aforementioned globalization process; it is also believed to boost the affective dimension, in the sense that students will feel more motivated to learn foreign languages; it is thought to help improve specific language terminology; it is believed to enhance students' intercultural communicative competence; it is believed to foster implicit and incidental learning by centering on meaning and communication; it is thought to trigger high levels of communication among teachers and learners, and among learners themselves; and, as a result of all the reasons mentioned above, it is also believed to improve overall language competence in the target language, in particular oral skills, CLIL purportedly being more beneficial for their development than traditional foreign language teaching approaches.

Scandinavia is one of the European areas where CLIL programmes have been widely put into practice. MerisuoStor [18] points out that in Finland, where a good command of the mother tongue is considered to be basic for all learning, one of the main worries has to do with the deleterious effects that CLIL might have on mother tongue literacy skills. This author compared groups of CLIL and regular students (whose classes were taught in Finnish) who were divided into two groups: 1) those who started school with a poor level of school readiness and 2) those with an excellent 
level of school readiness. The children were checked both at the beginning of first grade (6-7 years old) and at the end of second grade. The results showed no significant differences amongst the poor or excellent groups when the pupils' mother-tongue literacy skills were compared. Merisuo-Storm also observed that the students in CLIL classes held significantly more positive attitudes towards language learning. The female students in the monolingual classes in Finnish were more positive towards language learning, whereas among the CLIL groups no gender-based differences were observed. These results seem to confirm Marsh's [19] asseveration that CLIL classes can exert a positive influence on students' desire to learn and develop their language competence in the foreign language, especially among male students.

Since the effect of gender on language competence will also be analyzed in this paper, attention will be paid to the gender variable in the following lines. Research studies, which have widely covered gender issues during the last three decades, suggest that gender plays a significant role in foreign language performance, as there seems to be a female oriented culture that spreads the idea that learning foreign languages is a feminine terrain [20] and, subsequently, male students feel less confident and obtain worse scores [21, 22]. Research studies undertaken in different contexts show that women are more inclined to study foreign languages and second languages and they usually outperform their male counterparts [23, 24]. However, CLIL programmes seem to help blur these gender-based differences. A study of foreign language learners by Schmidt, Boraie and Kassagby [25] may help to explain this. They concluded that females were better foreign language learners because they were more intrinsically motivated, whereas males expressed more extrinsically motivated reasons. This is why CLIL programmes may help balance out gender differences, as male students might feel more motivated to learn both the language and the subject matter, enabling them to obtain higher scores in the subject concerned.

In another Scandinavian country, namely Sweden, Airey [26] points out that the number of studies which assess language competence attained through CLIL programmes both at pre-university and university levels is rather limited. As a matter of fact, this author acknowledges that he was unable to locate any research at university level. At pre-university level some studies seem to demonstrate that the improvement of English language skills in CLIL programmes is higher than that achieved in regular monolingual classes. However, Airey does not consider this evidence reliable, as the researchers did not assess language competence and simply asked the participants for their opinions. Since the respondents were involved in experimental programmes, their attitude and comments were positive, but not reliable in Airey's opinion. He highlights that, curiously enough, the only two studies $[27,28]$ which actually did measure foreign language competence, found no significant differences between the CLIL groups and regular classes. Airey [29] concludes that "despite the many variables affecting the measured learning outcomes, this is still somewhat surprising given the level of self-selection associated with this type of schooling", as the CLIL students are usually above average when it comes to grades, motivation and language skills/interest. Even though both groups of students were matched for different variables (motivation, intelligence, sociocultural status etc.), it is striking that no differences emerged between the CLIL and regular programmes.

In Norway, Hellekjaer [30] examined whether the level of English proficiency provided by upper secondary education was enough for the students to succeed in higher education CLIL courses, due to the fact that Norwegian universities do not offer English for academic purposes. In the study the participants had to complete the IELTS Reading for Academic Purposes Module Test and the scores of both CLIL and non-CLIL classes were compared. The objective was to ascertain whether upper-secondary EFL instruction develops reading skills sufficiently for students to manage English textbooks later on at university level. The results suggested that this assumption (students' sufficient reading skills) was questionable, since $66 \%$ of the participants scored poorly. When the non-CLIL groups were compared with the CLIL ones, among the former only $33 \%$ scored satisfactorily whereas this percentage was significantly higher among the latter, namely $74 \%$. The author rounds up his research by concluding that the deficiencies observed in secondary education foreign language instruction are not unique to Norway and can be applied to many other European contexts. Hellekjaer's study thus seems to confirm the author's statement in the sense that foreign language teaching has plenty of room for improvement and CLIL can be a reliable means of achieving this objective. Hellekjaer, however, acknowledges that it would be advisable to replicate the study by using the IELTS overall proficiency measure, which comprises listening, speaking and writing apart from the reading test employed in his study.

After reviewing the results obtained in German speaking countries, Dalton-Puffer [31] states that the language learning outcomes of CLIL are satisfactory, as CLIL students attain a foreign language competence well above that of students enrolled on regular courses. A very interesting conclusion of Dalton-Puffer's revision has to do with the fact that, whereas those with a knack for foreign languages secure a high degree of competence even through conventional foreign language classes, in CLIL groups average students manage to significantly improve their FL command and therefore this approach would cater better for them. The author also makes the following enlightening remark:

"The grades (in Germany but also in many other countries) are norm-referenced in the sense that they are usually given relative to the level obtained by that particular group of learners (the class). This means that the actual grades or marks given tend towards a normal distribution even though an average grade in a CLIL class expresses a higher absolute level of language competence than in a regular class [31]”.

The need exists therefore to evaluate both CLIL and nonCLIL groups using the same benchmarks to ascertain language competence precisely and discern which skills a CLIL approach complements most, as we intend to do in this paper.

According to Dalton-Puffer, certain languagecompetence aspects benefit more from CLIL. Thus, receptive 
skills, vocabulary (the lexicon is said to reflect the greatest gain, as it is usually explicitly treated in CLIL classes), morphology, creativity, risk-taking, fluency, quantity, and affective outcomes would gain most from this approach, whereas syntax, writing, informal language, pronunciation and pragmatics would remain unaffected. Coyle and Marsh [32,33] also assert that there is theoretical basis which complies with the idea that CLIL boosts risk-taking, problem solving, vocabulary learning skills, grammatical awareness, attitudes, linguistic spontaneity (talk), and addresses gender issues in motivation. This is why the development of the different language skills, in particular aspects such as fluency and syntax, and the relationship between gender and language competence will also be addressed in this paper.

The contradictory results gathered in Sweden when compared to those obtained in Norway and Germany do show just how necessary further studies are in order to identify the purported benefits of CLIL. In Catalonia, one of the 17 autonomous communities that make up Spain, the following quotation by Escobar and Pérez-Vidal [34] -when describing a multilingual school where a CLIL approach was adoptedalso shows the need to undertake studies in this area, as the words in italics (my emphasis) seem to suggest:

"In this sense, we believe that the learners involved in this CLIL programme are very likely to develop a higher command of English than otherwise they would have in conventional curricula. They will probably also be much better equipped to function in a university setting, both academically and socially, and later on professionally in multilingual Europe, as a result of good educational practice."

The italicized likely and probably need clarifying and that is why the development of language competence in CLIL programmes has to be carefully investigated to shed light on the possible language gains it entails.

The last variable to be considered in this paper is the sociocultural status. Most studies that have focused on the degree of competence attained in a foreign language tend to analyze the family's socioeconomic status (their income), whereas the family's sociocultural status is generally disregarded. Research [35] suggests that comparison of the socioeconomic class does not consider all the differences in a home environment, as socioeconomic class is just a simple and partial measure of the students' environmental background. For this reason parental occupation may summarize differences very inadequately. Lasagabaster and Laurén [36, 37] also observed that the sociocultural status variable had a greater effect on the learning of an L2/L3 than the socioeconomic status, for which it can be regarded a very influential variable when comparing different groups of learners. Bourdieu's [38] cultural capital thesis would also give theoretical support to the justification for using sociocultural status as a variable. According to Bourdieu students from privileged backgrounds are more likely to acquire a background in high culture (cultural capital) from which they can benefit at school. In educational terms this author maintains that those students who have habitus (cultural background) and dispositions (positive attitudes to school, high culture, social advantage, motivation, parental support, etc.) tend to be more successful than those who do not have them, which is why the former can obtain returns in the form of academic achievement and degree attainment. Consequently, it may be asserted that sociocultural status is an important variable in the process of learning a foreign language. Equating one's sociocultural status with the educational achievement of one's parents may seem controversial, since it can be argued that it may take more than just one's educational level to construct one's sociocultural identity. Nevertheless, in this article it has been considered that in previous studies carried out in the Basque [39] and Flemish [40] contexts and where the participant's sociocultural status was equated with one parent's educational achievement, the variable sociocultural status happened to exert a significant influence on the language competence attained by the students.

In the same vein, Furnham and Heaven [41] point out that social class has an effect on children's attitudes towards learning and academic performance in general. However, in this paper we will hypothesize that a CLIL approach helps diminish the impact of social class on language competence, as immersion programmes have demonstrated in the Canadian context. The use of the L2 as a means of communication boosts motivation among all students, creates an atmosphere that facilitates L2 use and allows students to make progress according to their learning styles and different learning rhythms. In this enriching context (either immersion or CLIL), the differences observed in traditional foreign language teaching contexts when the sociocultural status is considered seem to vanish [42].

\section{THE BASQUE CONTEXT}

The present research study was undertaken in the Basque Country, a Spanish bilingual autonomous community in which both Basque and Spanish are official languages, and therefore taught at school from the outset. Currently $35 \%$ of the Basque population can speak Basque fluently, although this percentage in much higher among children and teenagers as a result of the bilingual programmes available in the Basque educational system. Spanish is the majority language and all Basque citizens can speak it fluently.

In the case of the Basque Country the implementation of CLIL programmes is relatively new, the approach having blossomed over the last five years. The Department of Education of the Basque autonomous government has set up an experimental programme through which some state schools have started to implement CLIL programmes. The first programmes were only offered in English, but since the 2007-08 academic year six experimental CLIL programmes in French have also been implemented. The University of the Basque Country has also established a Plurilingualism Programme whose aim is to boost CLIL at university level. In fact, in the 2008-09 academic year 95 different subjects will be taught in English and French. It is an increasing trend which requires thorough research and assessment before education authorities make important decisions, such as extending these experimental programmes to the whole Basque educational system. This paper intends to provide results as far as the development of language proficiency is concerned.

The findings of research carried out in northern and central European contexts cannot necessarily be extrapolated to southern European contexts, as the situation in the north is far removed from that of Spain. For instance, in Finland [43] 
or the Netherlands [44] all citizens are exposed to English on a daily basis, especially through television; in Sweden [45] there is real concern about the ever growing presence of English which has even forced the government to develop legislation to protect the Swedish language; or in Belgium [46] Flemish children already know 400 English words before first being exposed to English at school. In the Basque Country in particular and in Spain in general, English is not used for internal communication (unlike in the case in the aforementioned EU member states) and its role is mainly limited to international contacts. In fact, Spain (together with France, Germany and Italy) is one of the few European countries where all TV programmes and films are still dubbed, as a result of the eminent position enjoyed by the powerful dubbing industry. Moreover, and as was mentioned at the beginning, a very large percentage of Spanish citizens cannot hold a conversation in a language other than their mother tongue.

The European Commission has been funding work on CLIL for over a decade, on the grounds that this approach can provide communicatively meaningful opportunities for students to use the newly acquired language skills, while nurturing self-confidence. Moreover, it also provides the opportunity to be exposed to the language without requiring extra time in the curriculum. Yet, the Commission also points out that CLIL can be facilitated by the presence of native speakers, but this is not the usual case in the Basque Country and in most European countries [47], where the vast majority of teachers are not native speakers. This makes the Basque setting one worth examining in order to ascertain whether this fact has any influence on the students' linguistic achievement. There is no doubt that the lecturers command of the foreign language becomes a crucial factor in CLIL programmes [48], because if they cannot provide adequate input, the improvement of students' language competence may be at risk [49]. Studies are therefore required to analyze if the competence improvement attained via CLIL is worth the effort, as CLIL should only be introduced if the conditions to make it successful are met.

The answers provided by research studies may thus vary from one European member state to another one, as the economic, sociolingustic, political, social and cultural context may differ to a large extent [50]. The obvious differences regarding the presence and social knowledge of foreign languages between northern/central European countries and those in the south may also have an effect on the results obtained through the CLIL approach. And if the education system is bilingual the differences may be even greater. Could the urgent need for further research in contexts like the Basque Country be clearer?

\section{HYPOTHESES}

After reviewing previous studies in this field of research, the following hypotheses were put forward:

HP1: Students enrolled on a CLIL programme in the fourth year of secondary education would outperform their non-CLIL counterparts in all language skills and in the average English score.

HP2: Despite being a year younger on average, those students enrolled on a third-year secondary-education CLIL programme will catch up with their fourth-year secondary-education non-CLIL counterparts in all language skills and in the average English score.

HP3: There would be no statistically significant differences between male and female students enrolled in CLIL programmes.

HP4: There would be no statistically significant differences between students enrolled in CLIL programmes depending on their sociocultural status.

\section{THE SAMPLE}

The participants were 198 secondary education (SE henceforth) students who were enrolled in four different schools and all of whom had started to learn English as a foreign language at the age of 8 . With the objectives of this paper in mind, the sample was divided into three groups:

i. A first group made up of 28 students in the fourth year of secondary education (SE4) and who were 15-16 years old. All those included in this group had only been taught English as a subject and the time alloted to the teaching of English in their classes amounted to three hours per week. From now on this group will be labelled as the Non-CLIL SE4 group.

ii. A second group consisting of 113 students was also enrolled in SE4, but apart from English as a subject (3 hours per week), they had also been involved in a CLIL programme for two years. These groups had CLIL 4 hours per week, the subjects taught through English varying in each high school: history, computer science, religion, classical culture, sciences, or modern English literature. In the four participating schools one of these subjects received more attention -3 hours per week-, whereas just one hour was devoted to a second one usually computer science or religion-. This group will be labelled as CLIL SE4.

iii. The third group gathered 57 third-year SE students aged 14 to 15 . This group had participated in CLIL for just one year and the subjects they were taught through English were geography, technology, and religion. In this case students also had an average of 4 hours of CLIL per week plus the regular three hours per week of English as a language subject. These students will be labelled as CLIL SE3.

\section{INSTRUMENTS}

\section{English Tests}

FL competence was measured via English tests corresponding to grammar, listening, speaking and writing. The grammar and the listening skills were measured using the standardized Oxford Placement Test. As for the written test, students were asked to write a letter to an English family with whom they were supposed to stay with in summer. They were given total freedom regarding the approach to use and could utilize the syntactic structures and vocabulary they thought best. The speaking test was based on the frog story [51], a widely used instrument in which students are asked to describe what is going on in a series of 24 pictures. The frog story has been used in many different contexts all over the world with different languages and with children, teenagers and adults [52]. 
The overall competence in English was reached by adding together the results obtained in the four tests (grammar, listening, speaking and writing). As different evaluation scales were used for the various tests, Z-scores were employed, as these allow comparison between numerical variables which have been measured according to different scales. The average mark for these newly calculated Z-scores (average score) is 0 (nought), and positive values indicate above-average scores whilst negative values represent those below the average. The tests carried out made it possible to measure communicative as well as linguistic competence. The tests related to the language skills are tests which measure global communication aspects, while the grammar test concentrates on measuring more specific linguistic aspects.

All the language measures had been used in previous research with both CLIL and non-CLIL classes in the Basque Country and therefore were known to be appropriate for the population under scrutiny.

\section{METHOD}

The questionnaire and all the tests (apart from the speaking test) were written tests and completed in groups. The speaking test was undertaken on an individual basis in a separate class with just the examiner present and was recorded for later evaluation. The listening and grammar tests were marked following objective criteria, whereas the writing and speaking test were rated following a holistic approach. Thus the rating of the latter tests not just counted the number of mistakes or the presence of certain elements, but also took into account the communicative effect that the written and spoken texts produced in the reader/hearer.

The "profile" technique [53] was applied to evaluate the written tests, which consists of five scales referring to the different aspects under consideration:

- Content (30 points): this category considers the development and comprehension of the topic as well as the adequacy of the content of the text.

- Organisation (20 points): several factors are considered here, namely, the organisation of ideas, the structure and cohesion of the paragraphs, and the clarity of exposition of the main and secondary ideas.

- Vocabulary (20 points): this category deals with the selection of words, expressions and their usage. The appropriateness of the register used is also taken into account.
- Language usage (25 points): the use of grammar categories is examined, e.g. tense, number, subject-verb agreement in addition to word order and the use of complex syntactic structures.

- Mechanics (5 points): this criterion includes the evaluation of spelling, punctuation or the use of capitalisation.

Within each of these scales there are four bandings ("excellent to very good", "good to average", "fair to poor", and "very poor") which give the person marking a series of key words on which to base the specific evaluation criteria. The overall written score is arrived at by adding the scores for each of the scales, which varies from a minimum of 34 points to a maximum of 100 . The speaking test was evaluated by means of a holistic approach consisting of five scales which had been used before in the Basque context [54, 55]:

- Pronunciation (10 points): this scale deals with the accuracy and the communicative effect of the respondents' pronunciation.

- Vocabulary (10 points): in this category the selection of words, expressions and their usage are examined.

- Grammar (10 points): several factors are considered here such as accuracy and the communicative effect of the different grammatical categories produced.

- Fluency (10 points): in this case the students' oral production is analyzed taking into account the length, continuity and speed.

- Content (10 points): in the last category both the development and the adequacy of the content are examined.

As in the written test, each scale consisted of four bandings. The minimum points score was 5 points and the maximum 50.

\section{RESULTS}

The first two hypotheses will be analyzed together. The results obtained by means of ANOVA analyses are apportioned in Table 2.

First of all let us compare the results of the CLIL and non-CLIL SE4 groups apportioned in Table 2 (the results of the CLIL SE3 groups will be dealt with later on). As expected, the CLIL groups significantly outstripped their nonCLIL counterparts in every single test and in the overall English competence score. As can be observed in Table 3, the resulting differences in the case of both the speaking (pronunciation, vocabulary, grammar, fluency and content)

Table 1. Results (Minimum and Maximum Scores, Mean Score and Standard Deviation) Obtained in the English Tests by the Whole Sample

\begin{tabular}{|c|c|c|c|c|c|}
\hline Speaking & 198 & 17 & 44 & 32.22 & 4.18 \\
\hline Grammar & 198 & 26 & 90 & 53.16 & 11.97 \\
\hline Listening & 198 & 23 & 85 & 64.53 & 9.09 \\
\hline
\end{tabular}


Table 2. Mean Score in the English Tests: CLIL Versus Non-CLIL Groups

\begin{tabular}{|c|c|c|c|c|}
\hline English Tests & Groups & Mean & SD & $\mathbf{F}$ \\
\hline \multirow{2}{*}{ Speaking } & CLIL SE4 & 33.48 & 3.97 & \multirow{2}{*}{$11.862 *$} \\
\hline & CLIL SE3 & 31.19 & 5.12 & \\
\hline \multirow[t]{2}{*}{ Writing } & Non-CLIL SE4 & 73.17 & 15.84 & \multirow[t]{2}{*}{$12.884^{*}$} \\
\hline & CLIL SE3 & 77.50 & 8.63 & \\
\hline \multirow[t]{3}{*}{ Grammar } & Non-CLIL SE4 & 37.96 & 5.78 & \multirow[t]{3}{*}{$39.077^{*}$} \\
\hline & CLIL SE4 & 56.93 & 11.05 & \\
\hline & CLIL SE3 & 53.14 & 9.96 & \\
\hline \multirow[t]{3}{*}{ Overall English competence } & Non-CLIL SE4 & -2.34 & 2.74 & \multirow[t]{3}{*}{$37.329^{*}$} \\
\hline & CLIL SE4 & 1.68 & 2.30 & \\
\hline & CLIL SE3 & -0.38 & 2.39 & \\
\hline
\end{tabular}

$* p<0.05$.

Table 3. Scales of the Speaking and Writing Tests: Non-CLIL SE4 Versus CLIL SE4

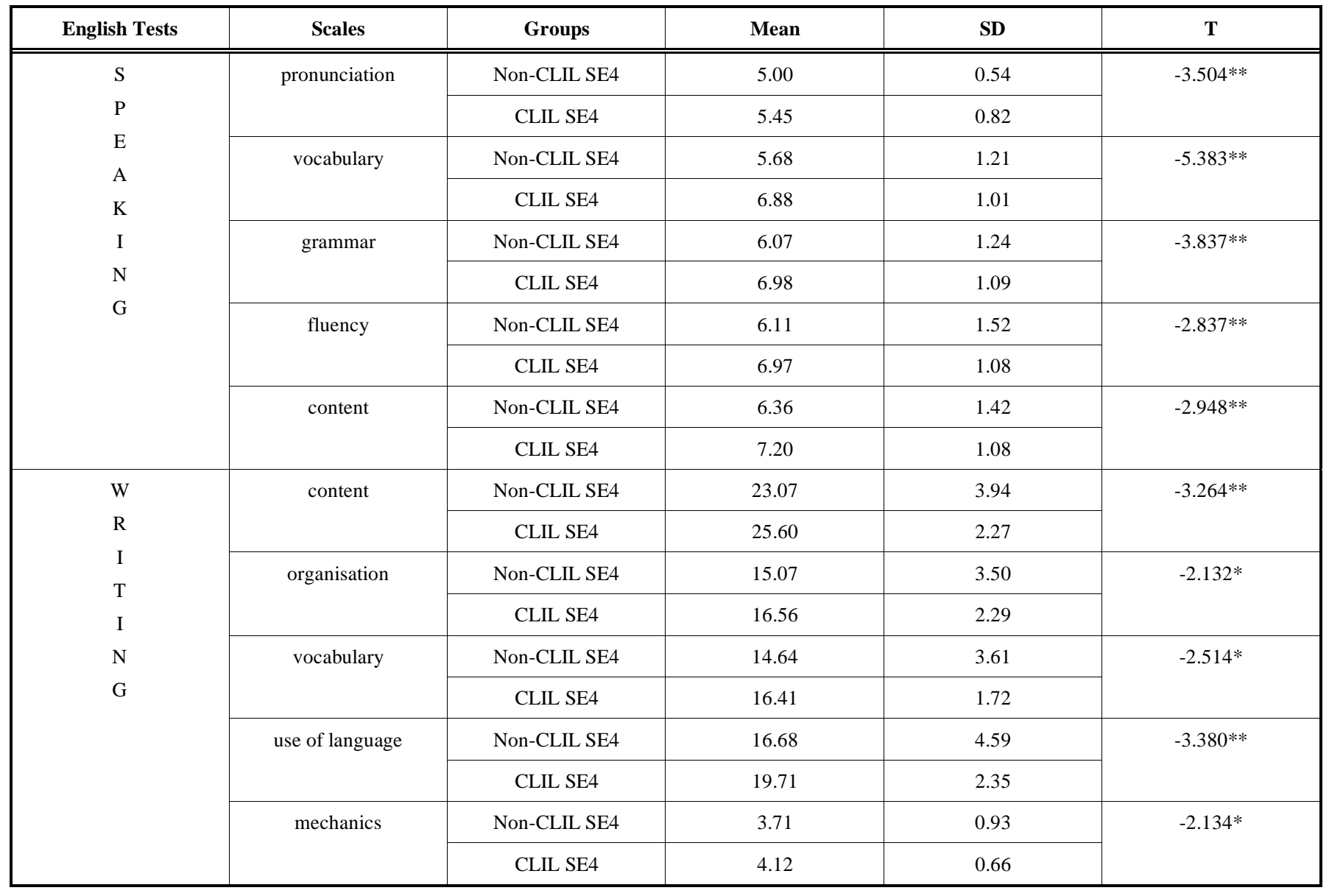


and writing (content, organisation, vocabulary, use of language and mechanics) tests were significant in every single one of the scales that make up each language-skill test. Consequently, it can be concluded that the CLIL approach has a clear impact on all the language skills and the grammar test analyzed in this study when students enrolled in the same grade are compared.

According to the second hypothesis, the students enrolled in SE3 CLIL programmes would catch up with the nonCLIL SE4 students, despite the fact that the former are a year younger. The results (Table 2) not only bear out this hypothesis, but also show that there are statistically significant differences in favour of the CLIL SE3 students in some of the tests. As a matter of fact, the CLIL SE3 groups scored higher than the non-CLIL SE4 in all tests but the listening (59.67 versus 59.79), as can be seen in Table 2 . In addition, the differences turned out to be significant in the grammar ( $\mathrm{p}$ $<0.05)$ and overall English competence ( $\mathrm{p}<0.05)$ tests. Therefore, not only did the CLIL SE3 catch up with their non-CLIL SE4 counterparts, but they also surpassed them in overall foreign language competence.

In order to examine the influence of the gender variable (third hypothesis) on language competence in CLIL programmes, T-test were performed considering just the CLIL SE4 group, in an attempt to check whether CLIL programmes help to diminish the differences observed in favour of female students when learning a foreign language. The percentage of female students $(58.4 \%)$ outweighed that of male students $(41.6 \%)$ for a total of 113 students. The results can be observed in Table 4 .

Contrary to expectations, female students still outperformed their male counterparts in all the English tests -but speaking, the only skill where no significant differences between male and female students were observed- and in overall English competence. Subsequently, it cannot be concluded that CLIL helps to balance English results on gender grounds, as female students still outscored their male peers.

The fourth hypothesis was aimed at evaluating the effect of students' sociocultural status on their language competence in the CLIL groups, results which are gathered in Table
5. The participants' social class was determined through the highest level of education attained by one of the parents [56] which led us to divide the sample into three groups: students whose parent had a primary education degree and who made up $14.4 \%$ of the sample; those whose parent had a secondary education degree, $20.7 \%$; and those whose parent obtained a university degree, $64.9 \%$.

In the case of the sociocultural status of the participants, the CLIL approach seems to diminish the effect of this variable on their foreign language competence, up to the point that there are no significant differences amongst the three groups of students irrespective of their parents' sociocultural status. As can be observed in the last column of Table 5 (the $F$ values), the differences between the three different groups are not statistically significant. In regular foreign language courses students whose parents had enjoyed greater educational opportunities usually obtain better scores in the second/foreign language [57-59], but this seems not to be the case once a CLIL approach is implemented.

\section{CONCLUSIONS}

Although during the last decade there has been a steady increase in the number of studies focused on CLIL programmes, it is obvious that this type of approach brings with it input related qualitative differences that affect foreign language competence and which deserve further consideration. CLIL is usually put under the microscope in contexts where a foreign language is used to teach majority language students [60], but in the Basque context analyzed in this paper it is implemented in learning contexts where both majority (Spanish as L1) and minority (Basque as L1) language students share the same class. Each context has its own peculiarities and the outcomes of CLIL programmes should therefore be studied from different perspectives and in diverse settings, enabling us to draw conclusions based on precise and case-specific evidence. By doing this our knowledge of the (dis)advantages of this particular kind of programme will be more accurate.

Our results confirm the effectiveness of CLIL even in a bilingual context where the foreign language concerned (English) is hardly ever used outside the school setting. The

Table 4. Gender and Language Competence in CLIL SE4

\begin{tabular}{|c|c|c|c|c|}
\hline English Tests & Gender & Mean & SD & $\mathbf{T}$ \\
\hline \multirow[t]{2}{*}{ Writing } & Male & 79.25 & 7.07 & \multirow[t]{2}{*}{$-3.987 *$} \\
\hline & Female & 84.62 & 7.03 & \\
\hline Grammar & Female & 59.81 & 9.08 & $-3.436^{*}$ \\
\hline \multirow[t]{2}{*}{ Listening } & Male & 65.94 & 7.50 & \multirow[t]{2}{*}{$-2.714^{*}$} \\
\hline & Female & 69.74 & 7.23 & \\
\hline Overall English competence & Male & 0.72 & 2.36 & $-3.950 *$ \\
\hline
\end{tabular}

$* \mathrm{p}<0.05$ 
Table 5. Sociocultural Status and Language Competence in CLIL SE4

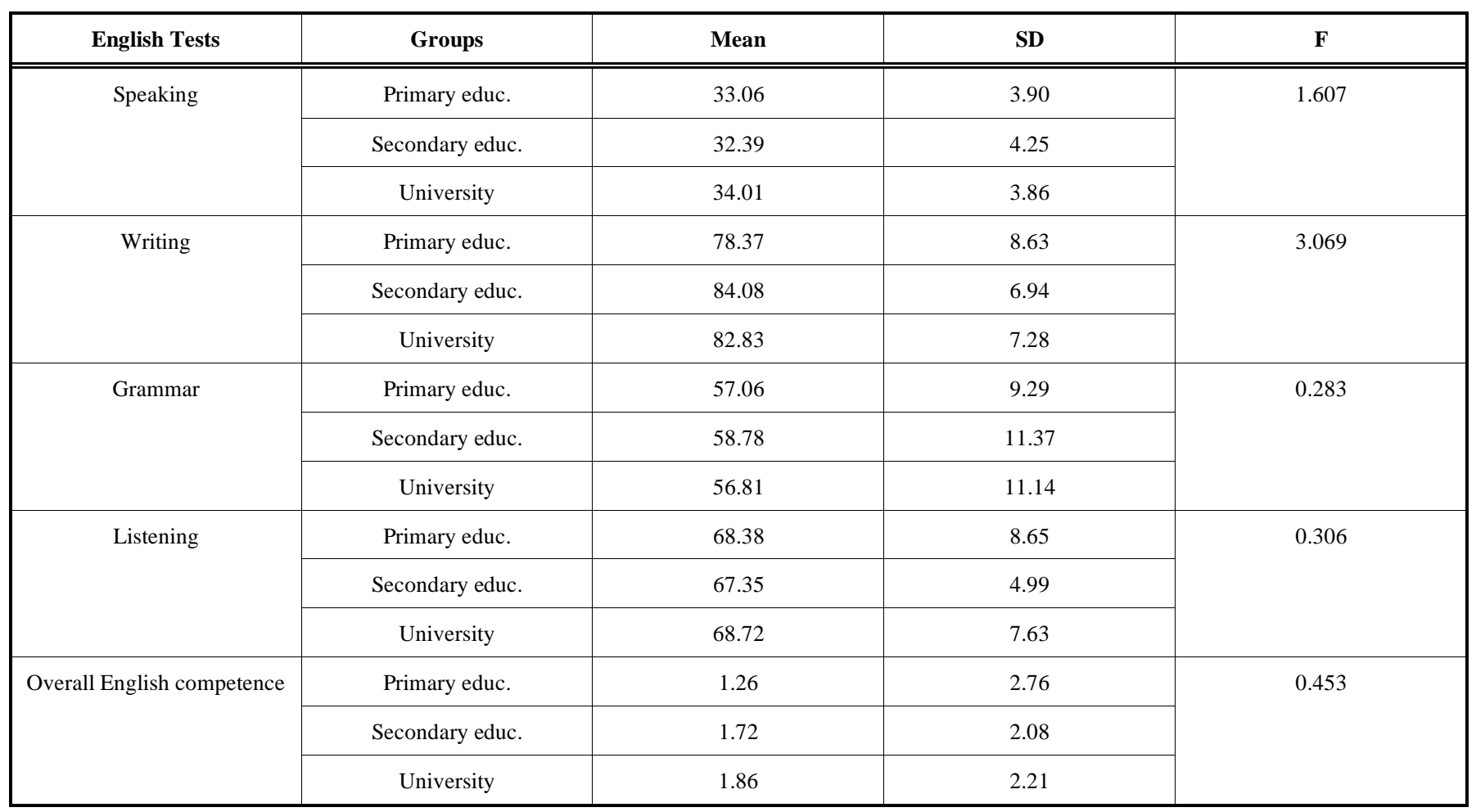

$* \mathrm{p}<0.05$.

better language performance of CLIL SE4 students when compared to non-CLIL SE4 students is reflected in every single test and in all the different scales that make up the writing and speaking tests; that is to say, CLIL exerts a positive influence on all the language aspects measured in the present study. The review of studies completed in Germany by Dalton-Puffer showed CLIL advantages concerning receptive skills, vocabulary and fluency, but our results also show an improvement of other aspects such as writing and pronunciation which seemed to remain unaffected in the German context. Therefore, in the Basque context the advantages seem to be even more obvious than those revealed in studies undertaken in Germany.

In any case, it has to be considered that students who chose the demanding CLIL programmes may have been more academically gifted and more motivated than their nonCLIL counterparts. However, Collins, Halter, Lightbown and Spada [61] make the following considerations, which can also be applied to the present study:

"Because the study was carried out in an existing educational context, some variables were difficult or impossible to control. Although this places certain limitations on the interpretations and the conclusions that may be drawn from the study, research of this type also has advantages. Summarizing Cronbach's approach to validity, Lynch [62] argues that the advantage of comparing existing programs is a gain in ecological validity that can actually contribute to the generalizability of the findings, provided steps are taken to properly document the context, procedures and results".
The CLIL approach has only been implemented on an experimental basis and all those students who are enrolled in these courses have freely decided to do so. In the case of this study it is possible that the CLIL students could be more gifted and motivated to learn English as a foreign language than their non-CLIL counterparts, and this is obviously a question to be considered. However, these differences do not invalidate the present study's findings, as stated in the quotation above.

Moreover, not only did the CLIL SE4 outperform the non-CLIL SE4 group (which bore out our first hypothesis), but the CLIL SE3 even outscored the non-CLIL SE4 despite the former being a year younger, a proven disadvantage in formal and traditional foreign language learning contexts wherein cognitive maturity plays a paramount role [63, 64]. According to the second hypothesis, there would be no significant differences between the CLIL SE3 and the nonCLIL SE4 groups. The results not only confirmed this, but even produced significant differences in the grammar test and the overall English competence in favour of the younger CLIL students. Thus, the positive effects of CLIL seem to remain even when the CLIL students are a year younger than the control students.

The results obtained in this study may help to shed some light on the combined effect of early foreign language learning and a CLIL approach and provide answers to some practical questions that are usually posed to language planners. Intensity becomes a key issue and the distribution of instruction time comes to the fore. Intensity has been considered in the Canadian context [65], where the distributed learning condition (a programme where students received approximately 2 hours per day of exposure to ESL over the full 
school year) has been found to have no advantage over massed instruction (where students spent most of every school day in ESL classes for 5 months of one school year). Whereas the psychological literature had found clear advantages for distributed practice, Collins et al. conclude that the different findings from the L2 classroom are not surprising. In fact, the finding that no linear relationship between the amount of instruction time and the amount of learning was observed in the Canadian context was probably due to the fact that the kind of learning that takes places in a formal learning context reaches a plateau or ceiling and the subsequent simple addition of more exposure does not automatically produce a proportional increase in learning [66-68]. Since intensive foreign language learning does not seem to be the solution, the CLIL approach may turn out to be a much more reasonable, effective and productive course of action if students' command of the foreign language is to be improved.

As a matter of fact, Egiguren [69] observed in a study completed in the Basque Country that students who had started learning English at the age of 8 caught up with the control group which had started English at 4 in just a year and a half. The teaching of Arts in English from the age of 8 among the former was enough to eliminate significant differences between the two groups by the time they had all reached the age of 10 . Most European education systems have decided to bring forward students' first contact with the foreign language, but after analyzing results obtained in different contexts (such as Norway, Germany or Spain) CLIL clearly demands more attention and the economic, material and human resources devoted to early teaching could turn out more cost-effective if CLIL were given priority.

As far as gender is concerned, studies undertaken in many different parts of the world show a trend in which female students are usually better foreign language learners than male students [70-72], although a previous study [73] came to the conclusion that CLIL helped to eradicate these differences. Similarly, Marsh [74] and Coyle [75] also consider that CLIL can address gender issues in language learning, but more studies are needed to support such a statement. Our findings, however, do not tally with the results obtained by Merisuo-Storm and the opinions expressed by Coyle and Marsh (our third hypothesis being refuted) regarding the CLIL approach; hence, further studies are called for. The gender issue has to be further examined and, if future results happen to coincide with ours, it will be necessary to analyze in depth the reasons for these gender-based differences. Foreign language skills are equally positive for both male and female citizens and the necessary measures should be implemented in order to smooth out the differences revealed in this study, as their disappearance should be the objective of any education system.

Our last hypothesis was confirmed and students benefited from the CLIL approach irrespective of their sociocultural status, as no differences were observed when the participants' parents' backgrounds were considered. Previous studies undertaken in the Basque and Flemish contexts [76, 77] had observed significant differences after equating student's sociocultural status with the level of their parents' educational achievement. The present results do not concur with the two studies above, but this could be due to the socially- equalizing effect of the use of a foreign language in the communicatively meaningful situations that can be created in CLIL classrooms on language competence. Second language acquisition researchers have paid little attention to social class as a variable due to the fact that their work has been seen as predominantly psychological rather than social [78], which is why this paper has focused on this variable in an attempt to help fill this gap. However, the construction of one's sociocultural identity is a complex process, which is why more studies centered on the relationship between students' sociocultural status and second language acquisition are needed, since there is no doubt that the social and cultural milieu in which learners grow up determine their beliefs and behaviour $[79,80]$.

The learning of content matter through a foreign language involves not only changing the language of instruction, but also redesigning programmes to integrate both content and language goals. Since this study demonstrates that the CLIL approach is successful and helps to improve students' language competence even in contexts where English has little social presence and is hardly ever used outside the school setting (unlike in other northern and central European countries), analysis of the methodology used and observation of the teachers involved in CLIL programmes should occupy a leading position on the list of researchers' priorities, as it promises to be a very fruitful area.

The learning of foreign languages through the CLIL approach is an attractive challenge, and this is especially so in contexts such as the one analyzed in this paper where the two co-official languages (Basque and Spanish) are already present in the curriculum. Neither optimistic nor alarming viewpoints should be accepted unless they are supported by empirical evidence. Therefore, the more research data there is available, the more theoretically sound the decisions made will be. Much is said about the importance of internationalization in higher education, but this will not succeed unless CLIL programmes are satisfactorily implemented in secondary education, as at university it may be too late to make our students proficient enough to benefit fully from an academic stay abroad. If this objective is to be achieved, much attention and efforts have to be put into CLIL programmes at secondary (and even primary) education. Last but not least, it has to be remembered that CLIL is becoming very popular not only in Europe, but all over the world [81, 82], and consequently this kind of research should be of interest to all those involved in many and diverse educational systems.

\section{ACKNOWLEDGEMENTS}

This study was supported by the grant HUM2006-09775C02-01/FILO awarded by the Spanish Ministry of Education and Science, and the grant IT-202-07 awarded by the Department of Education, University and Research of the Basque Government. I would also like to thank the anonymous reviewers for their helpful and enriching comments, although any inaccuracies or mistakes that remain are obviously my own responsability.

\section{REFERENCES}

[1] European Commission. Europeans and their languages. Special Eurobarometer 243. Brussels: European Commission 2006. 
[2] Wilkinson R. Integrating content and language. Meeting the challenge of a multilingual higher education. Maastricht: Maastricht University 2004.

[3] Eurydice. Content and language integrated earning (CLIL) at school in Europe [Online]. 2006 Available from: http://www.eurydice.org/portal/page/portal/Eurydice/showPresentat ion? pubid=071EN

[4] Coyle D. Content and language integrated learning: towards a connected research agenda for CLIL pedagogies. Int J Biling Edu Bilingual 2007; 10: 543-562.

[5] Coyle D. Content and language integrated learning: towards a connected research agenda for CLIL pedagogies. Int $\mathrm{J}$ Bilingual Education Bilingualism 2007; 10: 543-562.

[6] Eurydice. Content and language integrated earning (CLIL) at school in Europe [Online]. 2006 Available from: http://www.eurydice.org/portal/page/portal/Eurydice/showPresentat ion? pubid=071EN

[7] Muñoz C. Age-related differences in foreign language learning. Revisiting the empirical evidence. Int Rev Appl Linguist (in press).

[8] Turnbull M, Lapkin S, Hart D, Swain M. Time on task and immersion graduates' French proficiency. In: Lapkin S. Ed. French second language education in Canada: empirical studies, Toronto: University of Toronto Press 1998; pp. 31-55.

[9] García Mayo MP, García Lecumberri ML. Age and the acquisition of English as a foreign language. Clevedon: Multilingual Matters 2003.

[10] Muñoz C, Ed. Age and the rate of foreign language learning. Clevedon. Multilingual Matters 2006b.

[11] Dekeyser RM. The robustness of the critical period effect in second language acquisition. Stud Second Lang Acquis 2000; 22: 499-534.

[12] Eurydice. Key data on teaching languages at school in Europe. Brussels: European Commission 2005.

[13] Navés T. The long-term effects of an early start on writing in foreign language learning. Ph.D.[Dissertation]. Barcelona: University of Barcelona, 2006.

[14] Egiguren I. Atzerriko hizkuntza goiztiarraren eragina gaitasun eleaniztunean. Ph.D.[Dissertation]. Vitoria-Gasteiz, Spain: University of the Basque Country 2006.

[15] Muñoz C. The effects of age on foreign language learning: the BAF project. In: Muñoz C, Ed. Age and the rate of foreign language learning, Clevedon: Multilingual Matters 2006a; pp. 1-40.

[16] Coyle D. CLIL-A pedagogical approach from the European perspective. In: Van Deusen-Sholl N, Hornberger NH, Eds. Encyclopedia language and education. Second and foreign language education, $2^{\text {nd }}$ edition, Volume 4, New York: Springer Science+Business Media LLC 2008; pp. 97-111.

[17] Marsh D. Language awareness and CLIL. In: Cenoz J,. and Hornberger NH, Eds. Encyclopedia of language and education. Knowledge about language, $2^{\text {nd }}$ edition, Volume 6 , New York: Springer Science+Business Media LLC 2008; pp. 233-246.

[18] Merisuo-Storm T. Pupils' attitudes towards foreign-language learning and the development of literacy skills in bilingual education. Teaching Teacher Edu 2007; 23: 226-235.

[19] Marsh D. Using languages to learn and learning to use languages. Finland: University of Jyväskylä 2000.

[20] Kobayashi Y. The role of gender in foreign language learning attitudes: Japanese female students' attitudes towards learning English. Gender Edu 2002; 14: 181-197.

[21] Onwuegbuzie AJ, Bailey P, Daley CE. Cognitive, affective, personality, and demographic predictors of foreign language achievement. J Edu Res 2001; 94: 3-15.

[22] Oxford RL. Instructional implications of gender differences in language learning styles and strategies. Appl Lang Learn 1993; 4: 65-94.

[23] Pavlenko A, Piller, I. Language education and gender. In: May S, Hornberger NH. Eds. Encyclopedia of Language and Education, $2^{\text {nd }}$ edition, volume 1, Language policy and political issues in education, New York: Springer Science+Business Media LLC 2008; pp. 57-69.

[24] Sunderland J. Issues of language and gender in second and foreign language education. Lang Teach 2000; 33: 203-223.

[25] Schmidt R, Boraie D, Kassagby, O. Foreign language motivation: international structure and external connections. In: Oxford RL, Ed. Language learning motivation: pathways to the new century Hawaii: University of Hawaii 1996; pp. 9-20.
[26] Airey J. Can you teach it in English? Aspects of the language choice debate in Swedish higher education. In: Wilkinson R, Ed. Integrating content and language. Meeting the challenge of a multilingual higher education, Maastricht: Maastricht University 2004; pp. 97-108.

[27] Knight M. Third and final report on English at Ebersteinska Skolan. In: Näslund L, Ed. Engelskspråkiga tekniska studievägar vid Ebersteinskaskolan I Norrköping. Utvärdering av en försöksverkamhet. Stockholm: Skolöverstyrelsen 1990.

[28] Washburn L. English immersion in Sweden. A case study of Röllingby High School 1987-1989. Stockholm: University of Stockholm 1997.

[29] Airey J. Can you teach it in English? Aspects of the language choice debate in Swedish higher education. In: Wilkinson R, Ed. Integrating content and language. Meeting the challenge of a multilingual higher education, Maastricht: Maastricht University 2004; pp. 97-108.

[30] Hellekjaer G. Unprepared for English-medium instruction: a critical look at beginner students. In: Wilkinson R, Ed. Integrating content and language. Meeting the challenge of a multilingual higher education, Maastricht University 2004; pp. 147-171.

[31] Dalton-Puffer C. Outcomes and processes in content and language integrated learning (CLIL): current research from Europe. In: Delanoy W, Volkmann L, Eds. Future perspectives for English language teaching. Heidelberg: Carl Winter 2007.

[32] Coyle D. The relevance of CLIL to the European Commission's language learning objectives. In: Marsh D, Ed. CLIL/EMILE -The European dimension: actions, trends and foresight potential, European Commission 2002.

[33] Marsh D. Language awareness and CLIL. In: Cenoz J,. and Hornberger NH, Eds. Encyclopedia of language and education. Knowledge about language, $2^{\text {nd }}$ edition, Volume 6 , New York: Springer Science+Business Media LLC 2008; pp. 233-246.

[34] Escobar C, Pérez-Vidal C. Teacher education for the implementation of a content and language integrated approach (CLIL) in the school system. In: Wilkinson R, Ed. Integrating content and language. Meeting the challenge of a multilingual higher education, Maastricht University 2004; pp. 402-415.

[35] Baker C. Foundations of bilingual education and bilingualism. $2^{\text {nd }}$ edition. Clevedon: Multiling Matters 1996.

[36] Lasagabaster D. Learning English as an L3. ITL Rev Appl Linguist 1998; 121-122: 51-84.

[37] Laurén U. The written production of bilingual and monolingual students. Performance and creativity. Vaasa, Finland: Universitas Wasaensis 1994.

[38] Bourdieu P. The forms of capital. In: Halsey AH, Lauder H, Brown P, Wells AS, Eds. Education: culture, economy, and society, Oxford: Oxford University Press 1997; pp. 40-58.

[39] Lasagabaster D. Learning English as an L3. ITL Rev Appl Linguist 1998; 121-122: 51-84.

[40] Dewaele JM. Predicting language learners' grades in the L1, L2, L3 and L4: the effect of some psychological and sociocognitive variables. Int J Multilingual 2007; 4: 169-197.

[41] Furnham A, Heaven P. Personality and social behaviour. London: Arnold 1998.

[42] Genesee F. What do we know about bilingual education for majority language students? In: Bhatia TK, Ritchie W, Eds. Handbook of bilingualism and multiculturalism. Malden, MA: Blackwell 2004; pp, 547-576.

[43] Hyrkstedt I, Kalaja P. Attitudes toward English and its functions in Finland: a discourse-analytic study. World Engl 1998; 17: 345-357.

[44] van Essen A. English in mainland Europe -a Dutch perspective. World Engl 1997; 16: 95-103.

[45] Berg EC, Hult FM, King, KA. Shaping the climate for language shift? English in Sweden's elite domains. World Engl 2001; 20: 305-319.

[46] Goethals M. English in Flanders (Belgium). World Engl 1997; 16: 105-114.

[47] Kurtán Z. Foreign-language-medium instruction in Hungarian higher education. In: Wilkinson R. Ed. Integrating content and language. Meeting the challenge of a multilingual higher education, Maastricht: Maastricht University 2004; pp. 126-136.

[48] Brinton MD, Master P. New ways in content-based instruction. Alexandria, VA: TESOL 1997.

[49] Sercu L. The introduction of English-medium instruction in universities. A comparison of Flemish lecturers' and students' language 
skills, perceptions and attitudes. In: Wilkinson R. Ed. Integrating content and language. Meeting the challenge of a multilingual higher education, Maastricht: Maastricht University 2004; pp. 547555 .

[50] Wilkinson R. Integrating content and language. Meeting the challenge of a multilingual higher education. Maastricht: Maastricht University 2004.

[51] Mayer M. Frog, where are you? New York: Dial Press 1969.

[52] MacWhinney B. The CHILDES project: tools for analysing talk, Third edition. Mahwah, NJ: Lawrence Erlbaum 2000

[53] Jacobs H.L, Zinkgraf SA, Wormuth DR, Hartfield VF, Hughey JB. Testing ESL composition. Newbury: Rowley 1981.

[54] Cenoz J, Valencia JF. Additive trilingualism: evidence from the Basque Country. Appl Psycholinguist 1994; 15: 195-207.

[55] Lasagabaster D. The effect of knowledge about the L1 on foreign language skills and grammar. Int J Biling Edu Bilingual 2001; 4: 310-331

[56] Dewaele JM. Predicting language learners' grades in the L1, L2, L3 and L4: the effect of some psychological and sociocognitive variables. Int J Multilingual 2007; 4: 169-197.

[57] Baker C. Foundations of bilingual education and bilingualism. $2^{\text {nd }}$ edition. Clevedon: Multilingual Matters 1996

[58] Lasagabaster D. Learning English as an L3. ITL Rev Appl Linguist 1998; 121-122: 51-84.

[59] Laurén U. The written production of bilingual and monolingual students. Performance and creativity. Vaasa, Finland: Universitas Wasaensis 1994

[60] Dalton-Puffer C. Outcomes and processes in content and language integrated learning (CLIL): current research from Europe. In: Delanoy W, Volkmann L, Eds. Future perspectives for English language teaching. Heidelberg: Carl Winter 2007.

[61] Collins L, Halter RH, Lightbown PM, Spada, N. Time and the distribution of time in L2 instruction. TESOL Quarterly 1999; 33: 655-680.

[62] Lynch BK. Language program evaluation: theory and practice. Cambridge: Cambridge University Press 1996.

[63] García Mayo MP, García Lecumberri ML. Age and the acquisition of English as a foreign language. Clevedon: Multilingual Matters 2003.

[64] Muñoz C, Ed. Age and the rate of foreign language learning. Clevedon. Multilingual Matters 2006b.

[65] Collins L, Halter RH, Lightbown PM, Spada, N. Time and the distribution of time in L2 instruction. TESOL Quarterly 1999; 33: 655-680.

[66] Collins L, Halter RH, Lightbown PM, Spada, N. Time and the distribution of time in L2 instruction. TESOL Quarterly 1999; 33: 655-680.
[67] Heining-Boynton AL, Haitema T. A ten-year chronicle of student attitudes toward foreign language in the elementary school. Mod Lang J 2007; 91: 149-168.

[68] Rifkin B. A ceiling effect in traditional classroom foreign language instruction: data from Russian. Mod Lang J 2005; 89: 3-18.

[69] Egiguren I. Atzerriko hizkuntza goiztiarraren eragina gaitasun eleaniztunean. Ph.D.[Dissertation]. Vitoria-Gasteiz, Spain: University of the Basque Country, 2006.

[70] Kobayashi Y. The role of gender in foreign language learning attitudes: Japanese female students' attitudes towards learning English. Gender Edu 2002; 14: 181-197.

[71] Onwuegbuzie AJ, Bailey P, Daley CE. Cognitive, affective, personality, and demographic predictors of foreign language achievement. J Edu Res 2001; 94: 3-15.

[72] Oxford RL. Instructional implications of gender differences in language learning styles and strategies. Appl Lang Learn 1993; 4: 65-94.

[73] Merisuo-Storm T. Pupils' attitudes towards foreign-language learning and the development of literacy skills in bilingual education Teaching Teacher Edu 2007; 23: 226-235.

[74] Marsh D. Language awareness and CLIL. In: Cenoz J,. and Hornberger NH, Eds. Encyclopedia of language and education. Knowledge about language, $2^{\text {nd }}$ edition, Volume 6 , New York: Springer Science+Business Media LLC 2008; pp. 233-246

[75] Coyle D. Content and language integrated learning: towards a connected research agenda for CLIL pedagogies. Int J Bilingual Edu Bilingual 2007; 10: 543-562.

[76] Lasagabaster D. Learning English as an L3. ITL Rev Appl Linguist 1998; 121-122: 51-84.

[77] Dewaele JM. Predicting language learners' grades in the L1, L2, L3 and L4: the effect of some psychological and sociocognitive variables. Int J Multilingual 2007; 4: 169-197.

[78] Preston D. Sociolinguistics and second language acquisition. Oxford: Basil Blackwell 1989.

[79] Bourdieu P. The forms of capital. In: Halsey AH, Lauder H, Brown P, Wells AS, Eds. Education: culture, economy, and society, Oxford: Oxford University Press 1997; pp. 40-58.

[80] Ellis R. The study of second language acquisition. Oxford, England: Oxford University Press 1994.

[81] Knell E, Haiyan Q, Miao P, Yanping C, Siegel LS, Lin Z, Wei, Z. Early English immersion and literacy in Xi'an, China. Mod Lang J 2007; 91: 395-417.

[82] Nunan D. The impact of English as a global language on educational policies and practices in the Asia-Pacific region. TESOL Quart 2003; 37: 589-613.

(C) David Lasagabaster; Licensee Bentham Open

This is an open access article distributed under the terms of the Creative Commons Attribution License (http://creativecommons.org/licenses/by/2.5/), which permits unrestrictive use, distribution, and reproduction in any medium, provided the original work is properly cited. 